\title{
Aplikasi Arsitektur Metafora Pada Strategi Perancangan Lembaga Pendidikan Musik Di Surabaya
}

\author{
Ajeng Cita Anggraini' ${ }^{1}$ Rachmadi Nugroho² ${ }^{2}$ Suparno $^{3}$ \\ Program Studi Arsitektur, Universitas Sebelas Maret Surakarta ${ }^{1}$ \\ Email : ajeng_citt@student.uns.ac.id \\ Program Studi Arsitektur, Universitas Sebelas Maret Surakarta ${ }^{2}$ \\ Program Studi Arsitektur, Universitas Sebelas Maret Surakarta ${ }^{3}$
}

\begin{abstract}
The design proposal of Music School in Surabaya arises from society's increasing interest in the art of music, significant growth of Indonesian music industry which promises anyone involved likely gain, and underdeveloped infrastructure of the numerous, existing music school in Surabaya to cater the need in a bigger scale. Hence, the proposal focuses on the issue of designing Music School in Surabaya which provides space for music- and informal-music-education-related activities. It aims to serve as the place to learn music theories and perform musical art. The metaphorical architecture approach is applied to the design in order to reflect the function of the building. In other words, building observer will have ideas about the activities occurred inside through the façade which utilised the stated design approach.
\end{abstract}

Keywords: Metaphorical Architecture, Education Institute, Music, Surabaya

\section{PENDAHULUAN}

Pendidikan merupakan salah satu pilar penting dalam kemajuan dan kesejahteraan bangsa (Abu Ahmadi, dkk: 2015; Syaom: 2008). Dewasa ini, pendidikan non formal yang banyak dipilih oleh orang tua dan masyarakat luas adalah kursus musik. Hal ini didasari oleh pengaruh musik dalam pengembangan bakat dan kecerdasan mental seorang manusia.

Musik merupakan bahasa yang universal bagi semua orang yang mendengarnya. Musik merupakan salah satu jenis kesenian yang selalu diminati oleh semua orang dan dari semua kalangan. Dewasa ini, jenis musik yang sedang berkembang adalah musik modern. Orang-orang yang memiliki minat lebih terhadap musik modern membutuhkan suatu wadah untuk menambah ilmu tentang musik modern maupun untuk mengembangkan kemampuan bermusiknya. Salah satu wadah tersebut adalah keberadaan lembaga pendidikan yang khusus memberikan ilmu mengenai musik. Dalam dunia pendidikan Indonesia, pendidikan bermusik belum dianggap sebagai salah satu pendidikan yang memiliki prospek masa depan yang cerah. Faktanya dewasa ini, dengan majunya industri musik Indonesia membuat prospek yang bagus dan menguntungkan bagi orangorang yang menggeluti dunia musik, sehingga saat ini dirasa perlu untuk diciptakannya sebuah wadah yang dapat menampung keinginan orang-orang dalam bermusik melalui pendidikan musik. Perancangan Lembaga Pendidikan Musik ini juga mengingat banyaknya prospek karir di bidang musik yang dapat dicapai oleh lulusan Lembaga Pendidikan Musik ini. Prospek karir musik tersebut diantaranya menjadi musisi, komposer, penyanyi, produsen musik, dan sebagainya.

Dalam kaitannya dengan kebutuhan terhadap fenomena yang ada, yaitu fenomena meningkatnya minat remaja terhadap musik terutama di kota Surabaya yaitu kota metropolitan kedua setelah Jakarta, membutuhkan suatu wadah lembaga musik yang dapat mendukung minat remaja dalam 
meningkatkan hobi bermusiknya sekaligus menyalurkan hobi bermusiknya. Masyarakat kota Surabaya memiliki minat lebih terhadap dunia musik, hal ini terbukti dari banyaknya kegiatan musik yang diselenggarakan pada event-event tertentu serta keberadaan lembaga pendidikan musik nonformal atau kursus musik yang ada di Kota Surabaya.

Sementara itu, tempat kursus musik di Surabaya ditinjau dari segi bangunan dinilai kurang memadai untuk mewadahi kebutuhan kursus musik dengan skala yang lebih besar. Hal ini dikarenakan tempat kursus musik di Surabaya sebagian besar merupakan ruko-ruko kecil yang digunakan untuk pembelajaran semua aktifitas bermusik, yang mana hanya memiliki skala yang kecil. Sebagai salah satu wadah yang dapat menyalurkan hobi dan bakat bermusik, perlu adanya skala yang lebih besar dalam merancang lembaga pendidikan musik. Hal ini ditujukan agar semua apresiasi musik dapat dilakukan dan dikembangkan di bangunan tersebut. Oleh karena itu perlu adanya lembaga pendidikan musik nonformal dengan skala yang cukup besar salah satunya dengan perancangan Lembaga Pendidikan Musik Surabaya ini.

Dalam proses perancangan bangunan yang akan menjadi lembaga pendidikan nonformal yang bertemakan tentang musik, perlu adanya suatu jenis pendekatan yang mana pendekatan tersebut akan memiliki dampak yang signifikan baik bagi penghuni bangunan maupun bagi masyarakat yang melihat bangunan. Dalam perancangan Lembaga Pendidikan Musik ini, perancang menggunakan pendekatan yang mampu mengekspresikan wadah bagi fungsi yang ada di dalamnya (Antoniades, Anthony C: 1990). Teori perancangan yang relevan dengan fungsi dan aktifitas bangunan akan memudahkan orang mengetahui bahwa bangunan tersebut memiliki kesan, persepsi atau gambaran fungsi bangunan melalui ekspresi tampilan yang dominan. Oleh karena itu, perancang menggunakan pendekatan arsitektur metafora untuk diterapkan pada bangunan Lembaga Pendidikan Musik ini, yaitu dengan menunjukkan bentuk fisik dan non fisik pada bangunan.

\section{METODE}

Secara umum, untuk mencapai tujuan dan sasaran yang telah dirumuskan berdasar rumusan masalah, metode penyelesaian desain yaitu menggunakan metode arsitektur dengan pendekatan arsitektur metafora.

Konsep Pendekatan Arsitektur Metafora diterapkan dalam desain Lembaga Pendidikan Musik di Surabaya adalah sebagai berikut:

a) Dalam menentukan konsep Arsitektur Metafora yang akan diterapkan ke dalam bangunan Lembaga Pendidikan Musik, perlu adanya kajian terhadap konsep Arsitektur Metafora itu sendiri. Kajian konsep Arsitektur Metafora didapatkan dengan mengkaji dan menganalisis preseden yang ada yaitu bangunanbangunan yang telah menerapkan Pendekatan Arsitektur Metafora.

b) Kondisi Lembaga Pendidikan Musik yang akan didesain memerlukan observasi menyeluruh terhadap tempat-tempat kursus musik yang sudah ada, khususnya yang terdapat di Kota Surabaya.

c) Penentuan bentuk-bentuk benda atau elemen musik sebagai langkah awal dalam menerapkan elemen metafora ke dalam bangunan (Kojin Karatani : 1995). Pemilihan bentuk-bentuk tersebut didasarkan pada fungsi dan image bangunan agar tercipta keselarasan antara aktifitas di dalam bangunan terhadap penampilan bangunan.

d) Penerapan tata letak ruang berdasarkan prinsip pola hubungan ruang serta kesesuaian terhadap bentuk bangunan yang menerapkan Pendekatan Arsitektur Metafora.

e) Penerapan warna bangunan yang selaras dengan konsep Pendekatan Arsitektur Metafora. Penentuan warna untuk bangunan diterapkan agar tercipta keselarasan terhadap bentuk-bentuk metafora yang ada di dalamnya.

\section{HASIL DAN PEMBAHASAN}

Penerapan Pendekatan Arsitektur Metafora terhadap Lembaga Pendidikan Musik di Surabaya perlu adanya kajian tentang Arsitektur Metafora, yaitu Pendekatan Arsitektur Metafora melalui studi literasi dan 
Pendekatan Arsitektur Metafora melalui olah lapangan.

Perencanaan dan perancangan Lembaga Pendidikan Musik dengan Pendekatan Arsitektur Metafora di Surabaya terdapat beberapa analisis diantaranya.

A. Tapak

a) Penentuan Tapak

Tujuan: Penentuan Tapak bertujuan untuk mendapatkan tapak yang sesuai digunakan dalam perancangan Lembaga Pendidikan Musik.

Hasil:

Dari analisis penilaian pemilihan site di atas, maka diperoleh hasil site yang dipilih untuk Bangunan Lembaga Pendidikan Musik yang direncanakan adalah site 1 yaitu yang berada diantara Jalan Raya Diponegoro dan Jalan Dr. Soetomo, Kecamatan Tegalsari, Surabaya.

Batas batas tapak :

Timur terdapat rumah penduduk \& J1 Trunojoyo $(5 \mathrm{~m})$, selatan merupakan SPBU \& Jl Dr. Soetomo $(15 \mathrm{~m})$. sedangkan barat terdapat perkantoran dan Jl Raya Diponegoro (18 m), utara merupakan rumah penduduk.

b) Analisis Pencapaian

Tujuan: Tujuan dari analisis pencapaian adalah untuk mendapatkan jenis dan pola pencapaian dalam menuju tapak yang berupa Main Entrance (ME) dan Side Entrance (SE) untuk menghasilkan sirkulasi tapak yang nyaman bagi setiap pengguna.

Dasar Pertimbangan:

- Terdapat kemudahan akses menuju Main Entrance dari jalan utama

- Sirkulasi Main Entrance dan Side Entrance lancar dan tidak menimbulkan kemacetan

- Terdapat kemudahan akses menuju Main Entrance dan Side Entrance untuk pejalan kaki, pengguna kendaraan umum dan pengguna kendaraan pribadi

c) Klimatologis

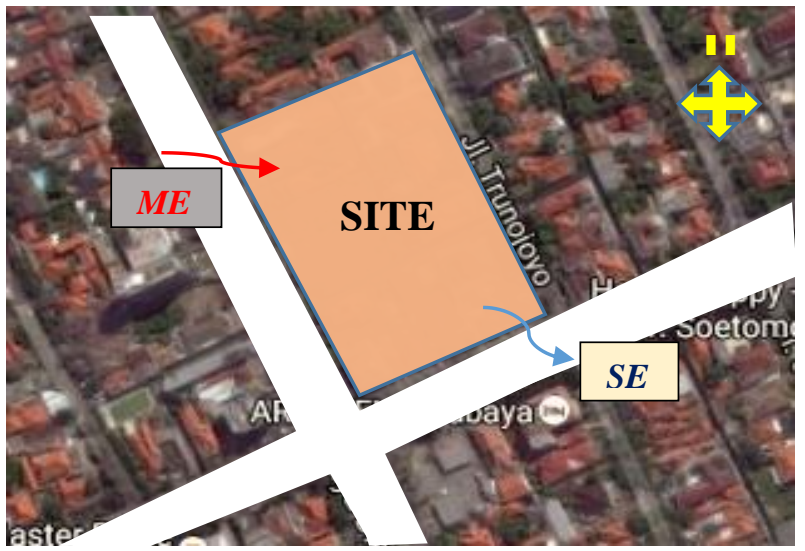

Gambar 1. Analisis Pencapaian Site

Tujuan: Tujuan dari analisis faktor klimatologis adalah untuk menentukan respon tapak dan bangunan terhadap faktor iklim yang terjadi di sekitar tapak. Faktor klimatologis yang akan di analisis adalah cahaya matahari dan arah angin.

Dasar Pertimbangan:

- Arah cahaya matahari yaitu dari timur ke barat. Dalam hal ini, zona yang membutuhkan cahaya matahari pagi adalah zona pendidikan. Hal ini bertujuan agar kegiatan pendidikan berjalan dengan baik dan kondusif.

- Pergerakan arah angin bergantung pada letak bangunan-bangunan tinggi di sekitar tapak serta jumlah vegetasi di sekitar tapak. Hal ini menentukan ketinggian massa bangunan yang akan direncanakan. Setiap massa bangunan setidaknya harus mendapatkan angin yang cukup.

- Pencahayaan alami dan penghawaan alami dioptimalkan bagi ruang-ruang dengan fungsi yang membutuhkan hal tersebut.

Hasil:

- Pemanfaatan cahaya matahari pagi di sisi timur yaitu dengan meletakkan ruang ruang yang membutuhkan cahaya pagi di sebelah timur, diantaranya yaitu ruang pendidikan dan ruang pengelola.

- Untuk mengatasi dan memanfaatkan cahaya matahari 
siang yang cukup panas, yaitu dengan memberi taman-taman dan pohon di sekitar bangunan dan menciptakan skylight di tengah bangunan untuk mengoptimalkan cahaya matahari yang masuk.

- Pengoptimalan penghawaan alami berupa perletakan bukaan pada massa bangunan yang berada di sisi barat laut yaitu pada zona pendidikan dan zona pengelolaan.

- Pemberian vegetasi untuk menyaring angin atau udara kotor di sisi tenggara tapak.

d) View dan Orientasi

Tujuan: Tujuan dari analisis view adalah untuk menentukan orientasi bangunan dalam tapak serta dapat mengetahui view yang baik dari dalam maupun luar tapak dengan tujuan untuk menunjang kebutuhan kegiatan dalam bangunan.

Hasil:

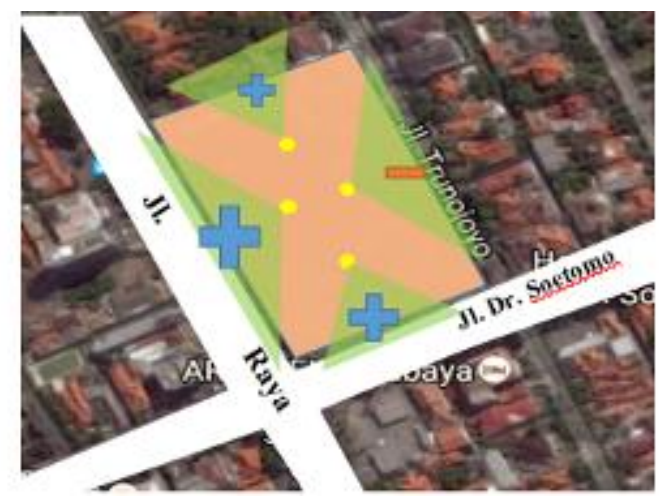

Gambar 2. Analisis View dan Orientasi

\section{e) Kebisingan}

Tujuan: Analisis kebisingan bertujuan untuk mengetahui sumber kebisingan agar bisa mengelompokkan fungsi ruang sesuai dengan kebutuhan dan ketahanannya terhadap kebisingan di sekitar tapak.

Hasil:

- Zona pertunjukan serta zona informasi dan promosi diletakkan pada sisi tapak yang memiliki kebisingan sangat tinggi dikarenakan kedua zona tersebut tidak terlalu membutuhkan ketenangan.

- Zona servis diletakkan pada sisi selatan yang memiliki kebisingan tinggi dikarenakan zona tersebut tidak membuthkan fungsi ruang dengan ketenangan yang berlebih.

\section{B. Peruangan}

Tujuan: Adanya aktivitas yang dilakukan oleh pelaku kegiatan (user) menyebabkan adanya suatu tuntutan ruang sebagai wadah dari segala aktivitas tersebut. Analisis kebutuhan ruang bertujuan untuk mengetahui ruangan apa saja yang dibutuhkan user pada bangunan Lembaga Pendidikan Musik yang direncanakan ini. Hasil:

Tabel 1. Kelompok Kegiatan

\begin{tabular}{|l|lr|r|r|}
\hline No. & \multicolumn{1}{|l|}{ Kelompok Kegiatan } & $\begin{array}{r}\text { Kebutuhan } \\
\text { Luas Lantai }\end{array}$ & $\begin{array}{r}\text { Renc. } \\
\text { Jumlah } \\
\text { Lantai }\end{array}$ & $\begin{array}{c}\text { Luas Lantai } \\
\text { Dasar Minimal }\end{array}$ \\
\hline 1 & Kegjatan Pendidikan Musik & $1397,09 \mathrm{~m}^{2}$ & 3 & $455,59 \mathrm{~m}^{2}$ \\
\hline 2 & Kegiatan Pertunjakan Musik & $1690,7 \mathrm{~m}^{2}$ & 1 & $1580,7 \mathrm{~m}^{2}$ \\
\hline 3 & $\begin{array}{l}\text { Kegiatan Informasi dan } \\
\text { Promosi }\end{array}$ & $457,78 \mathrm{~m}^{2}$ & 1 & $457,78 \mathrm{~m}^{2}$ \\
\hline 4 & Kegiatan Pengelola & $258,85 \mathrm{~m}^{2}$ & 1 & $293,85 \mathrm{~m}^{2}$ \\
\hline 5 & Kegiatan Servis & $654,9 \mathrm{~m}^{2}$ & 1 & $654,9 \mathrm{~m}^{2}$ \\
\hline 6 & Aras Parkit & $1131,1 \mathrm{~m}^{2}$ & 1 & $3044 \mathrm{~m}^{2}$ \\
\hline Total & $5548,42 \mathrm{~m}^{2}$ & & $6602,92 \mathrm{~m}^{2}$ \\
\hline
\end{tabular}

C. Bentuk dan Tampilan

Tujuan: Tujuan dari analisis gubahan massa bangunan adalah untuk menentukan bentuk gubahan yang sesuai dengan fungsi kebutuhan ruang dan keterikatannya dengan pendekatan arsitektur metafora.

Bangunan Lembaga Pendidikan Musik yang direncanakan ini memiliki bentuk fasad bangunan yang mencerminkan aktifitas di dalamnya (James C. Snyder: 1979). Bangunan ini memiliki massa majemuk yaitu terdapat 5 massa bangunan dimana setiap massa bangunan mewadahi aktivitas zona yang berbeda. Dalam keterkaitan antara aktivitas dengan fasad bangunan, pendekatan yang diterapkan dalam bangunan ini merupakan pendekatan arsitektur metafora.

Hasil: 
Massa Bangunan Zona Pendidikan (Massa Utama)
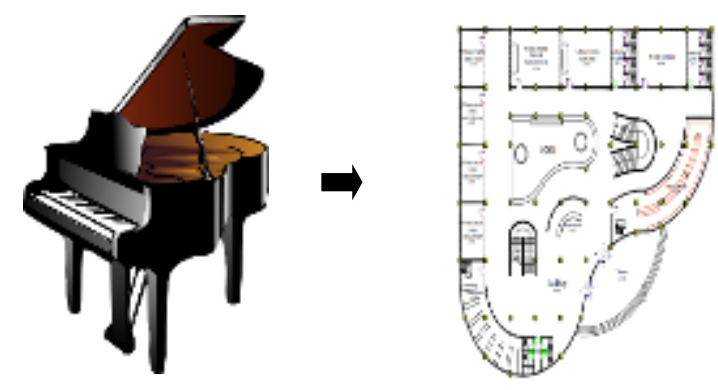

Gambar 3. Grand Piano dan Denah Pendidikan

Bentuk massa bangunan pendidikan pada Lembaga Pendidikan Musik mengadaptasi bentuk Grand Piano. Untuk memperkuat kesan atraktif pada tampilan fasad depan massa bangunan pendidikan, maka ditambahkan massa untuk menimbulkan kesan adanya 'irama' ke dalam bentuk bangunan.

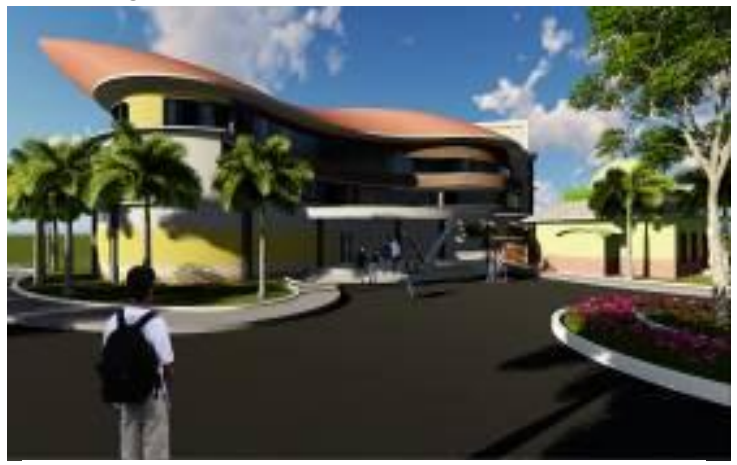

Gambar 4. Eksterior Bangunan Pendidikan

Massa Bangunan Zona Pertunjukan

Bentuk massa bangunan zona pertunjukan mengadaptasi bentuk elemen musik drum yang mana drum memiliki bentuk-bentuk lingkaran.

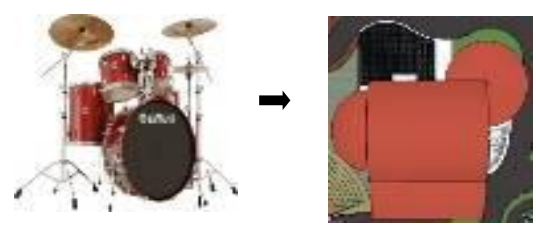

Gambar 5. Drum dan Bangunan Pertunjukan

Pada bangunan zona pertunjukan, bagian ruangan yang menggunakan bentuk lingkaran seperti drum adalah ruang retail musik dan lobby ruang pertunjukan.

Bentuk lingkaran digunakan untuk menunjukkan kesan dinamis (D.K Ching:
1994), sedangkan bentuk persegi digunakan pada bagian ruang pertunjukan untuk memaksimalkan ruang.

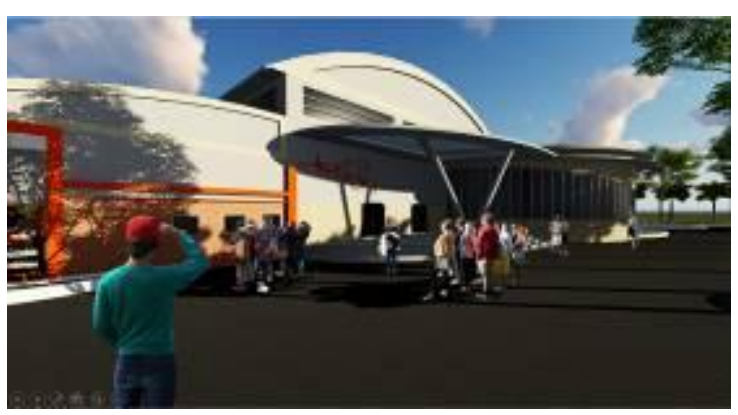

Gambar 6. Eksterior Bangunan Pertunjukan

Analisis Tata Massa Bangunan

Tujuan: Tujuan dari analisis tata massa bangunan adalah untuk mengatur komposisi letak massa bangunan yang disesuaikan dengan jenis zona kegiatan yang ada serta keterkaitannya dengan konsep pendekatan metafora.

Hasil:

Pada bangunan Lembaga Pendidikan Musik yang direncanakan ini, pola tata massa bangunan akan menggunakan organisasi massa cluster. Dalam komposisi cluster dapat menerima bentuk-bentuk massa dengan ukuran dan pola yang berbeda-beda tetapi tetap berhubungan satu sama lain.

D. Utilitas dan Struktur

a) Analisis Sistem Sub-Structure

Tujuan: Tujuan dari analisis sistem Sub-Structure adalah untuk menentukan sistem sub struktur (pondasi) yang dapat mendukung beban bangunan.

Hasil:

Berdasarkan kondisi site dan massa bangunan, maka Bangunan Lembaga Pendidikan Musik yang direncanakan ini menggunakan sistem sub-struktur berikut:

- Sistem pondasi foot plate

Sistem pondasi foot plate merupakan sistem pondasi yang diterapkan pada bangunan berlantai rendah dengan konstruksi menggunakan beton bertulang. 
- Sistem pondasi batu kali

Sistem pondasi batu kali merupakan pondasi yang strukturnya terbuat dari pasangan batu kali yang disusun sedemikian rupa.

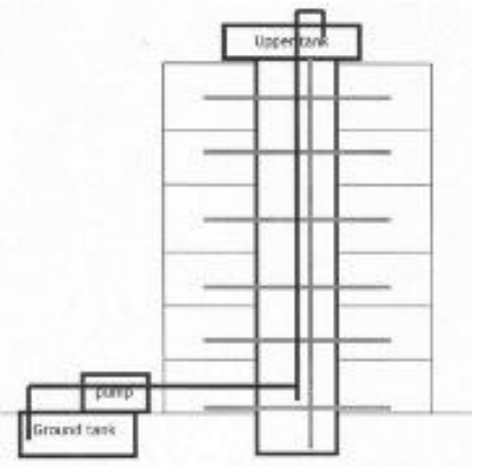

Gambar 7. Sistem Distribusi Tangki Atap

b) Analisis Sistem Super Structure

Tujuan: Tujuan dari analisis super structure adalah untuk menentukan struktur yang digunakan pada bagian badan bangunan seperti dinding, kolom dan balok.

Hasil:

Secara keseluruhan konstruksi sub struktur yang akan digunakan dalam bangunan Lembaga Pendidikan yang direncanakan ini adalah struktur rigid frame, yaitu struktur yang terdiri dari elemen linier balok yang saling terhubung pada ujung-ujungnya.

c) Analisis Sistem Upper Structure

Tujuan: Tujuan dari analisis sistem upper struktur adalah untuk menentukan struktur atap yang sesuai dengan massa bangunan.

Hasil:

Pada perancangan bangunan ini menggunakan system struktur atas sebagai berikut.

- Struktur rangka atap baja ringan

- Atap Sky Light

- Atap dak beton

d) Analisis Sistem Akustik Ruang

Dalam perencanaan bangunan Lembaga Pendidikan Musik, terdapat beberapa massa di dalamnya. Pada beberapa massa tersebut, terdapat massa bangunan atau ruangan yang membutuhkan sistem akustik maupun tidak. Ruang yang membutuhkan sistem akustik yang baik adalah ruang pertunjukan, ruang rekaman, ruang studio musik, ruang latihan bersama dan ruang-ruang praktek bermusik (Leslie Doelle: 1972).

e) Analisis Sistem Air Bersih Pada bangunan Lembaga Pendidikan Musik yang direncanakan ini akan menggunakan sumber air yang berasal dari PDAM, serta menerapkan sistem distribusi tangki atap (down feed system).

f) Analisis Pembuangan Air Kotor Pada sistem pembuangan air kotor, bangunan Lembaga Pendidikan Musik yang direncanakan ini menerapkan sistem pembuangan terpisah. Pembuangan air kotor bangunan ini dibagi menjadi tiga jenis. Yaitu air limbah toilet yang dialirkan ke septictank, air limbah pantry yang disalurkan ke riol kota, serta air hujan yang disaluran melalui talang-talang menuju tanah.

g) Analisis Sistem Jaringan listrik

Sumber listrik yang akan digunakan dalam memasok kebutuhan listrik pada Lembaga Pendidikan Musik yang direncanakan ini antara lain:

\section{- PLN}

Yaitu sumber listrik yang berasal dari jaringan kota yang dikelola oleh pemerintah dan memiliki daya listrik besar.

- Genset (Generator Set)

Yaitu perangkat mesin diesel yang digunakan saat listrik PLN mengalami pemadama

\section{KESIMPULAN}

Lembaga Pendidikan Musik di Surabaya menerapkan Pendekatan Arsitektur Metafora. Pendekatan Arsitektur Metafora diterapkan pada fasad bangunan (eksterior) di beberapa bangunan. Dalam kaitannya dengan strategi perancangan, perlu adanya beberapa hal yang perlu diperhatikan dalam penerapan Pendekatan Arsitektur Metafora, diantaranya adalah:

a) Identifikasi lokasi didirikannya bangunan. Bangunan dengan konsep Pendekatan 
Arsitektur Metafora perlu adanya point of interest. Keberadaan point of interest juga ditentukan oleh letak lokasi didirikannya bangunan. Oleh karena itu, bangunan yang menerapkan Pendekatan Arsitektur Metafora harus terletak di lokasi yang strategis agar dapat menjadi landmark di kota tersebut.

b) Penerapan konsep Pendekatan Arsitektur Metafora perlu adanya beberapa kajian pertimbangan desain sebelum merancang bangunan dengan Pendekatan Arsitektur Metafora. Kajian itu antara lain yaitu dengan mempelajari penerapan Arsitektur Metafora yang sudah ada melalui observasi lapangan ataupun studi literasi melalui preseden bangunan dengan Arsitektur Metafora.

c) Desain dengan Pendekatan Arsitektur Metafora mengutamakan tampilan bangunan. Oleh karena itu, penerapan objek-objek yang akan dimetaforakan menjadi penting dalam desain perancangan. Sehingga desain dengan Pendekatan Arsitektur Metafora tidak hanya dapat digunakan sesuai fungsinya tapi juga dapat dinikmati secara visual.

\section{REFERENSI}

Ahmadi, Abu., Nur Uhbiyati. 2015. Ilmu Pendidikan. Jakarta: Rineka Cipta.

Antoniades, Anthony C. 1990. "Poetics Of Architecture” Theory of Design, Van

Nostrand Reinhold: New York.

Barliana, M. Syaom. 2008. Universitas Pendidikan Indonesia, Jurnal TERAS, Vol VIII, No 1

D.K Ching. 1994. Arsitektur, Bentuk, Ruang dan Susunannya. Erlangga: Jakarta.

Doelle, Leslie L. 1972. Akustik Lingkungan. Erlangga: Jakarta.

James C. Snyder, Catanese, Anthony James. 1979. Introduction to Architecture. McGraw-Hill.

Karatani, Kojin. 1995. Architecture as Metaphor: Language, Number. Money. 